\title{
Corticospinal Inputs to Primate Motoneurons Innervating the Forelimb from Two Divisions of Primary Motor Cortex and Area 3a
}

\author{
Claire L. Witham, ${ }^{1}$ Karen M. Fisher, ${ }^{1}$ Steve A. Edgley, ${ }^{2}$ and Stuart N. Baker ${ }^{1}$ \\ Institute of Neuroscience, Newcastle University, Newcastle upon Tyne NE2 4HH, United Kingdom, and ${ }^{2}$ Department of Physiology, Development and \\ Neuroscience, Cambridge University, Cambridge CB2 3DY, United Kingdom
}

Previous anatomical work in primates has suggested that only corticospinal axons originating in caudal primary motor cortex ("new M1") and area 3a make monosynaptic cortico-motoneuronal connections with limb motoneurons. By contrast, the more rostral "old M1" is proposed to control motoneurons disynaptically via spinal interneurons. In six macaque monkeys, we examined the effects from focal stimulation within old and new M1 and area 3a on 135 antidromically identified motoneurons projecting to the upper limb. EPSPs with segmental latency shorter than $1.2 \mathrm{~ms}$ were classified as definitively monosynaptic; these were seen only after stimulation within new M1 or at the new M1/3a border (incidence $6.6 \%$ and $1.3 \%$, respectively; total $n=27$ ). However, most responses had longer latencies. Using measures of the response facilitation after a second stimulus compared with the first, and the reduction in response latency after a third stimulus compared with the first, we classified these late responses as likely mediated by either long-latency monosynaptic $(n=108)$ or non-monosynaptic linkages $(n=108)$. Both old and new M1 generated putative long-latency monosynaptic and non-monosynaptic effects; the majority of responses from area 3a were non-monosynaptic. Both types of responses from new M1 had significantly greater amplitude than those from old M1. We suggest that slowly conducting corticospinal fibers from old M1 generate weak late monosynaptic effects in motoneurons. These may represent a stage in control of primate motoneurons by the cortex intermediate between disynaptic output via an interposed interneuron seen in nonprimates and the fast direct monosynaptic connections present in new M1.

Key words: corticospinal; EPSP; macaque; monosynaptic

\section{Significance Statement}

The corticospinal tract in Old World primates makes monosynaptic connections to motoneurons; previous anatomical work suggests that these connections come only from corticospinal tract (CST) neurons in the subdivision of primary motor cortex within the central sulcus ("new M1") and area 3a. Here, we show using electrophysiology that cortico-motoneuronal connections from fast conducting CST fibers are indeed made exclusively from new M1 and its border with 3a. However, we also show that all parts of M1 and 3a have cortico-motoneuronal connections over more slowly conducting CST axons, as well as exert disynaptic effects on motoneurons via interposed interneurons. Differences between old and new M1 are thus more subtle than previously thought.

\section{Introduction}

The primary motor cortex (M1) is the principal cortical source of mammalian motor output and a major origin of the corticospinal tract (CST). In Old World primates such as man, the CST forms monosynaptic connections to spinal motoneurons; these appear

\footnotetext{
Received Nov. 11, 2015; revised Jan. 7, 2016; accepted Jan. 13, 2016.

Author contributions: C.L.W., S.A.E., and S.N.B. designed research; C.L.W., K.M.F., S.A.E., and S.N.B. performed research; C.L.W. and S.N.B. analyzed data; C.L.W., K.M.F., S.A.E., and S.N.B. wrote the paper.

This work was supported by the Wellcome Trust. We thank Terri Jackson, Lee Reed, and Norman Charlton for technical assistance; Paul Flecknell and Aurelie Thomas for anesthesia support; Caroline Fox and Denise Reed for theater nursing; and Demetris Soteropoulos for assistance with some of the dataset on pyramidal tract neuron conduction velocities.

The authors declare no competing financial interests.
}

important in the control of fine, fractionated movements, especially of the hand (Porter and Lemon, 1993). Whereas CST fibers originate from a broad area of the frontal and parietal cortices (Dum and Strick, 1991), recent anatomical work using trans-

This article is freely available online through the J Neurosci Author Open Choice option.

Correspondence should be addressed to Prof. Stuart Baker, Institute of Neuroscience, Henry Wellcome Building for Neuroecology, Newcastle University, Framlington Place, Newcastle upon Tyne NE2 4HH, UK. E-mail: stuart.baker@ncl.ac.uk.

D0I:10.1523/JNEUROSCI.4055-15.2016

Copyright $\odot 2016$ Witham et al.

This is an Open Access article distributed under the terms of the Creative Commons Attribution License Creative Commons Attribution 4.0 International, which permits unrestricted use, distribution and reproduction in any medium provided that the original work is properly attributed. 
synaptic retrograde tracing by rabies virus has shown that cortico-motoneuronal (CM) connections arise from only two anatomically defined zones: the caudal part of M1 (referred to as "new M1") and area 3a (Rathelot and Strick, 2006, 2009). Since intracortical stimulation within 3a usually does not produce movement (Sessle and Wiesendanger, 1982), Rathelot and Strick (2006) suggested that these CM cells project preferentially to $\gamma$ motoneurons responsible for fusimotor control. However, stimulus effects on muscle can be elicited from area 3 a (Wannier et al., 1991; Widener and Cheney, 1997), and there is a report of a single neuron in $3 \mathrm{a}$ that generated postspike facilitation in spiketriggered averages of electromyogram (Widener and Cheney, 1997), which is evidence of a CM connection to $\alpha$ motoneurons.

By contrast, the rostral part of M1 ("old M1") lacks CM cells defined by rabies virus labeling, even though electrical stimulation throughout M1 can elicit movements. It has been suggested that corticospinal axons originating in old M1 act on motoneurons predominantly via disynaptic pathways traversing spinal cord interneurons, either located in closely adjacent segments or in the high cervical cord (propriospinal cells). However, although it is straightforward to find interneurons within the primate cervical cord that respond to CST stimulation at the pyramids (Riddle and Baker, 2010), it has proven difficult to reveal evidence of disynaptic corticospinal effects on motoneurons in either anesthetized (Maier et al., 1998) or awake (Olivier et al., 2001) animals. Only by antagonizing feedforward glycinergic inhibition using systemic administration of strychnine can robust disynaptic corticospinal effects be produced in cervical motoneurons; these arise at least in part from $\mathrm{C} 3 / \mathrm{C} 4$ propriospinal interneurons (Alstermark et al., 1999). One issue may be that stimulation of the pyramid unselectively activates fibers with different functional roles, thereby recruiting both inhibitory and excitatory disynaptic systems together to no overt effect; this has also been proposed to occur using noninvasive magnetic stimulation in man (Nicolas et al., 2001). It is possible that focal stimulation of the old M1 subdivision might reveal disynaptic corticospinal effects in cervical motoneurons more readily.

We have investigated this issue directly by examining responses in primate forelimb $\alpha$ motoneurons after focal microstimulation of both M1 subdivisions and area 3a. Fast monosynaptic responses were recorded only after stimuli were delivered to new M1 and its immediate border with 3a. Longer-latency responses could be evoked from all stimulated regions; in some cases, these had properties consistent with monosynaptic connections from slower conducting fibers, and in others they appeared to be generated by oligosynaptic linkages.

\section{Materials and Methods}

All animal procedures were performed under United Kingdom Home Office regulations in accordance with the Animals Scientific Procedures Act (1986) and were approved by the Local Research Ethics Committee of Newcastle University. Recordings were made from six terminally anesthetized rhesus macaque monkeys (five female and one male; coded A, B, C, D, E, and $\mathrm{H}$ in this study; weights of 7.0, 10.4, 9.2, 6.8, 9.8, and $13.5 \mathrm{~kg}$, respectively).

Initial surgical preparation. Animals were sedated by intramuscular injection of ketamine $(10 \mathrm{mg} / \mathrm{kg})$; then deep anesthesia was induced with propofol (5-14 $\mathrm{mg} \cdot \mathrm{kg}^{-1} \cdot \mathrm{h}^{-1}$, i.v.). A tracheotomy was performed, and anesthesia was switched to sevoflurane inhalation (3-5\%) and an intravenous infusion of alfentanil $\left(7-23 \mu \mathrm{g} \cdot \mathrm{kg}^{-1} \cdot \mathrm{h}^{-1}\right)$ with artificial ventilation; this regimen was used to complete all major surgery. Central arterial and venous lines were inserted via the external carotid artery and external jugular vein. The bladder was catheterized. Peripheral nerves were exposed by dissection, and nerve cuff electrodes were placed around the median and ulnar nerves in the upper arm and wrist in addition to the radial nerve at the axilla and cubital fossa (deep branch). A laminectomy was then made exposing spinal segments C6-T1. The head was fixed in a stereotaxic frame, angled to produce $\sim 60^{\circ}$ neck flexion, and the spinal column was supported by vertebral clamps at high thoracic and midlumbar vertebrae. A bilateral pneumothorax was made. A craniotomy was made over the central sulcus on one side permitting access to M1 and area $3 \mathrm{a}$.

Implant of cortical stimulating electrodes. The anesthetic regimen was switched to intravenous infusions of midazolam (0.2-0.6 $\left.\mathrm{mg} \cdot \mathrm{kg}^{-1} \cdot \mathrm{h}^{-1}\right)$, alfentanil $\left(10-50 \mu \mathrm{g} \cdot \mathrm{kg}^{-1} \cdot \mathrm{h}^{-1}\right)$, and ketamine $\left(0.2-1.0 \mathrm{mg} \cdot \mathrm{kg}^{-1} \cdot \mathrm{h}^{-1}\right)$; this regimen was chosen to increase cortical excitability. Penetrations were made in the precentral and postcentral cortices with parylene-insulated stainless steel microelectrodes (1 M $\Omega$ impedance; Microprobe). These were connected to both a stimulator (A-M Systems model 2200; 18 biphasic pulses at $300 \mathrm{~Hz}, 0.2 \mathrm{~ms}$ per phase, intensity up to $100 \mu \mathrm{A}$ ) and a preamplifier (Neurolog NL100; Digitimer) using a relay that facilitated rapid switching between recording and stimulation conditions. The distinction between areas $3 \mathrm{a}, 3 \mathrm{~b}$, and 4 (M1) was made using a combination of receptive field testing (soft cotton bud to identify cutaneous receptive fields, joint manipulation to identify proprioceptive receptive fields) and intracortical microstimulation. This also allowed us to characterize the elbow, wrist, and digit representations of area 3a and M1. After trial penetrations for mapping, we positioned multiple electrodes to allow focal stimulation of each area during the main experiment. Electrodes were inserted individually, and the depth was optimized based on recordings and stimulus effects. Support rods made of lengths of 19G stainless steel tube were placed to span the craniotomy and fixed to the bone on either side using bone screws and dental acrylic. Each electrode was then fixed to these rods in turn using dental acrylic. Once the acrylic had set, the electrode was disconnected from the micromanipulator and the shaft bent out of the way to allow access for the next penetration. For monkeys A, B, C, and $\mathrm{H}$, nine stimulating electrodes were implanted in area 3a, caudal M1 (new M1; average depth of $4 \mathrm{~mm}$ in the central sulcus), and rostral M1 (old M1; average depth of $1.5 \mathrm{~mm}$ ). Three electrodes were implanted in each area at mediolateral locations corresponding to elbow, wrist, and digit-related sites (A, B and $\mathrm{C}$ ) or wrist and digits $(\mathrm{H})$. In monkeys $\mathrm{D}$ and $\mathrm{E}$, electrodes were implanted at two mediolateral locations related to digits across area 3a, caudal M1, and rostral M1 (total of 11 electrodes in D and 13 electrodes in E).

Anesthesia maintenance and monitoring. Motoneuron recordings took place over 12-24 h. During this period, the inspired oxygen concentration was reduced to $\sim 50 \%$ to avoid complications of oxygen toxicity consequent on long-term anesthesia. Fluid balance was maintained by infusion of Hartman's solution (to give a total infusion rate of 5 $\mathrm{ml} \cdot \mathrm{kg}^{-1} \cdot \mathrm{h}^{-1}$, including drug infusions). CNS edema was minimized by administration of methylprednisolone (initial loading dose of $30 \mathrm{mg} /$ $\mathrm{kg}$, i.v., followed by infusion of $5.4 \mathrm{mg} \cdot \mathrm{kg}^{-1} \cdot \mathrm{h}^{-1}$, i.v.). Antibiotics were administered by intravenous injection of cefotaxime every $8 \mathrm{~h}$ ( 250 $\mathrm{mg}$ per dose). The animal was kept warm via a thermostatically controlled pad and a blanket supplied with warm air. Throughout all surgery and experimental procedures, the animal's physiological condition and anesthetic level were ensured by continually monitoring end-tidal $\mathrm{CO}_{2}$ concentration, blood oxygen saturation, rectal and skin temperature, central arterial and venous blood pressure, and heart rate. Slowly rising trends in heart rate or arterial blood pressure were taken as evidence of waning anesthesia, and drug infusion rates were adjusted accordingly. During the experiment, peripheral nerve stimuli were given that would have provoked rapid changes in heart rate and blood pressure in the absence of adequate anesthesia and analgesia. Monitoring whether such changes occurred provided an additional indicator for adjusting the continual anesthetic infusions.

Motoneuron recording. Recordings were performed under neuromuscular blockade (atracurium, $0.5 \mathrm{mg} \cdot \mathrm{kg}^{-1} \cdot \mathrm{h}^{-1}$ ). Intracellular recordings were made from motoneurons using sharp glass micropipettes filled with potassium acetate (tip impedance, 3-20 M $\Omega$ ). The micropipettes were inserted into the ventral horn of the spinal cord, after removing the arachnoid and making a small pial patch. Motoneurons were identified 
by an antidromic response to stimulation of one or more nerve cuffs. This also permitted assignment of the motoneuron to a particular muscle group (upper arm extensors, forearm flexors, forearm extensors, or intrinsic hand muscles). After identification, synaptic responses to stimulation of cortical electrodes (1-4 biphasic shocks at $300 \mu \mathrm{A}, 0.2 \mathrm{~ms}$ per phase; trains used a $3 \mathrm{~ms}$ interstimulus interval; $4 \mathrm{~Hz}$ repetition rate) were recorded. Cortical electrodes were connected to a custom microcontroller-based system that used relays to direct the output of a single stimulator to one of 16 electrodes in turn; this allowed us to test all implanted electrodes, each with one to four shocks, in the minimum time. A single current return electrode was used in nearby temporal muscle for all cortical stimuli.

If recordings were stable and the motoneuron displayed EPSPs in response to two or more cortical electrodes, a conditioning protocol was used to provide information on the possible source of the effects. A conditioning stimulus was applied to one of the old M1 or area $3 \mathrm{a}$ electrodes, followed by a test stimulus to a new M1 electrode at an interval of $1-15 \mathrm{~ms}$. The test stimulus was a single shock at $100-300 \mu \mathrm{A}$ (depending on the size of the EPSP in response to the test stimulus), and the conditioning stimulus was one to three shocks at $300 \mu \mathrm{A}$. The responses to conditioning stimulus alone and test stimulus alone were also recorded.

During all motoneuron recordings, we also measured the surface volleys from a silver ball electrode placed on the cord dorsum close to the entry point of the intracellular electrode. Intracellular waveforms (AC signal used to assess EPSP height: gain, 200; bandpass, $3 \mathrm{~Hz}$ to $10 \mathrm{kHz}$; DC signal used to assess membrane potential: gain, 20; bandpass DC, $10 \mathrm{kHz}$; both sampling rate, 25,000 Hz), cord dorsum recordings (gain, 2000; bandpass, $30-5000 \mathrm{~Hz}$; sampling rate, $12,500 \mathrm{~Hz}$ ), and stimulus markers were captured to disk using a micro1401 interface and Spike2 software (Cambridge Electronic Design). Once all recordings were completed from a motoneuron, we repeated any stimuli that had produced effects, but with the electrode now in the extracellular space, to verify that responses were intracellular in origin and did not merely reflect massed local field potentials.

Histology. At the end of the experiment, electrolytic lesions were made for each of the cortical electrodes by passing a current of $100 \mu \mathrm{A}$ for $20 \mathrm{~s}$ (tip negative). The anesthesia was increased to a lethal level by administering intravenous propofol, and the animal was perfused through the heart with PBS followed by paraformaldehyde ( $4 \%$ formalin in PBS). The brain block containing sensorimotor cortex was removed and placed in $30 \%$ sucrose until it sank for cryoprotection; this was subsequently cut into $50 \mu \mathrm{m}$ parasagittal sections using a freezing microtome. Alternate sections were stained for parvalbumin (parvalbumin antibody; SigmaAldrich), neurofilament (SMA-32 antibody; Sternberger Monoclonals), and Nissl (cresyl violet). The reconstructions of electrode tip locations showed that a number of electrodes targeted to area 3a (as identified by electrophysiological methods) were actually placed on the border of M1 and area 3a. We separated these electrodes from those that were fully in area 3 a, denoting them as a fourth category "border." Example histological reconstructions of four electrode sites are shown in Figure $1 A$ (new M1, monkey B; old M1, monkey C; M1/area 3a border, monkey H; area 3a, monkey A).

Analysis. The cord dorsum responses to cortical stimulation were used to calculate the latency of the D and I waves (Fig. 1B). Axonal conduction velocity for each motoneuron was estimated based on the distance between the nerve cuff and the spinal cord and the latency of the antidromic response (Fig. 1B).

Conditioning experiment. In some experiments, stimuli were delivered to new M1 conditioned by prior stimulation of another area at different intervals, with the aim of determining whether the amplitude of the monosynaptic EPSP generated from new M1 was modified by the conditioning stimulus. To determine whether the response amplitude had changed, we generated the response expected from a linear sum of the responses to the conditioning and test stimuli given alone and its confidence limits using a Monte Carlo resampling procedure. One singlesweep response to the test stimulus alone and one response to the conditioning stimulus alone were selected at random from those available and summed with the appropriate conditioning interval. This procedure was repeated until the same number of summed responses was
A

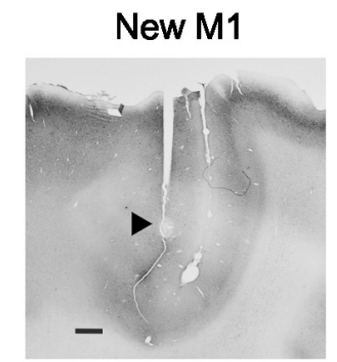

Area 3a/New M1 Border

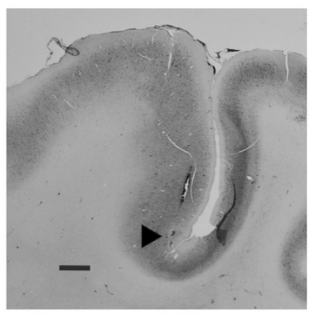

B
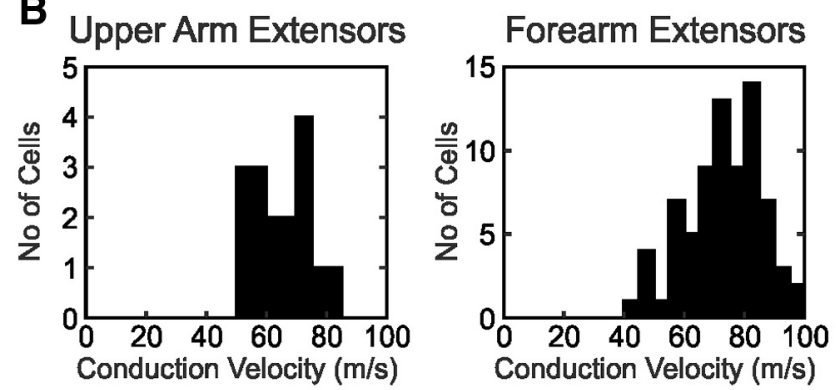

Forearm Flexors

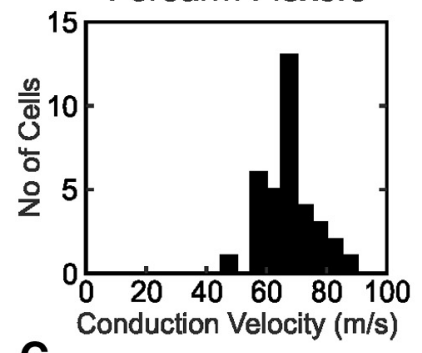

Intrinsic Hand Muscles

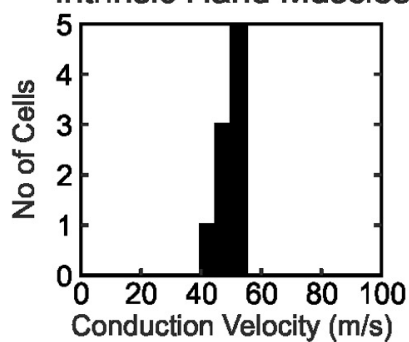

C

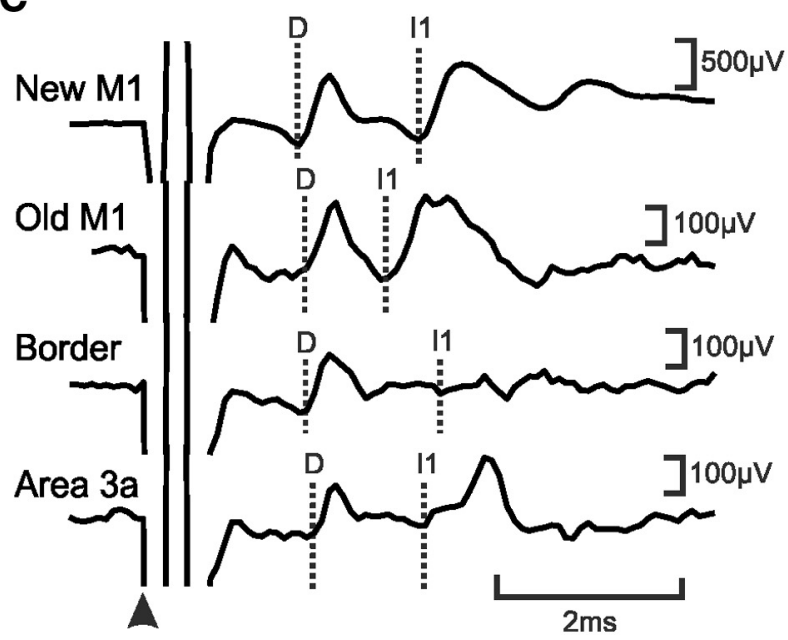

Figure 1. Methodology. A, Histological confirmation of the location of four cortical electrodes, each in a different animal. Black arrowheads indicate sites of electrolytic lesion. Scale bars, $1 \mathrm{~mm}$. $\boldsymbol{B}$, Histograms of conduction velocities for motoneurons recorded from the six monkeys for each of the four muscle groups. $C$, Average cord dorsum potentials to stimulation of electrodes shown in $A$ (single shock at $300 \mu \mathrm{A})$. The arrowhead indicates the stimulation time; dotted lines show the D and I waves. 
Table 1. Frequency and amplitude of D- and I-wave generation from different cortical areas

\begin{tabular}{|c|c|c|c|c|c|}
\hline Cortical stimulus site & $\begin{array}{l}\text { Number of sites } \\
\text { generating D } \\
\text { waves (percentage) }\end{array}$ & $\begin{array}{l}\text { Number of sites } \\
\text { generating I } \\
\text { waves (percentage) }\end{array}$ & $\begin{array}{l}\text { Number of sites } \\
\text { generating neither D } \\
\text { nor I waves } \\
\text { (percentage) }\end{array}$ & $\begin{array}{l}\text { Amplitude of D wave } \\
\text { (mean } \pm \text { SEM, } \mu \mathrm{V} \text { ) }\end{array}$ & $\begin{array}{l}\text { Amplitude of I1 wave } \\
\text { (mean } \pm \text { SEM, } \mu \mathrm{V} \text { ) }\end{array}$ \\
\hline New M1 & 14/18 (78\%) & 15/18 (83\%) & $3 / 18(17 \%)$ & $31.9 \pm 9.5$ & $27.5 \pm 9.2$ \\
\hline Border region & $5 / 6(83 \%)$ & $5 / 6(83 \%)$ & $1 / 6(17 \%)$ & $7.5 \pm 3.4$ & $4.0 \pm 1.3$ \\
\hline Area 3a & $2 / 10(20 \%)$ & $2 / 10(20 \%)$ & $8 / 10(80 \%)$ & $5.8 \pm 2.3$ & $2.4 \pm 1.3$ \\
\hline 0ld M1 & 10/14 (71\%) & 10/14 (71\%) & 4/14 (29\%) & $22.4 \pm 9.4$ & $28.5 \pm 12.8$ \\
\hline
\end{tabular}

obtained as actual conditioned responses; the average summed response was then calculated. The whole procedure was repeated 1000 times, yielding 1000 average responses distributed as expected on the null hypothesis of linear response summation. This allowed us to set confidence limits on the overall waveform and the response amplitudes. Actual conditioned amplitudes were considered to be suppressed if they were less than the $2.5 \%$ confidence interval and facilitated if they were higher than the $97.5 \%$ confidence interval of this expected waveform. The extent of the change was measured as follows:

$$
\% \text { Change }=\frac{\text { Actual Response }- \text { Expected Response }}{\text { Expected Response }} \times 100 \%
$$

Conduction velocity of pyramidal tract neurons. We supplemented the novel dataset reported in this study with a reanalysis of older data on pyramidal tract neurons (PTNs) in macaque M1. These recordings were obtained either in awake animals trained to perform a variety of behavioral tasks or in animals lightly sedated; full details of methods have been given in the primary publications (Baker et al., 2001; Wetmore and Baker, 2004; Witham and Baker, 2007; Soteropoulos and Baker, 2009; Williams et al., 2009; Soteropoulos et al., 2012; Koželj and Baker, 2014). Briefly, extracellular single-unit recordings were made using an Eckhorn microdrive (Thomas Recording) and glass-insulated platinum microelectrodes or tetrodes (tip impedance, 1-2 M $\Omega$ ). Units were identified as PTNs if they responded at consistent latency to stimulation of the pyramidal tract at the medulla through chronically implanted electrodes; the antidromic nature of the response was confirmed using a collision test (Baker et al., 1999).

When the microelectrodes were penetrated through the dura mater, we noted the depth at which cell activity was first seen. Any PTNs recorded $>2.5 \mathrm{~mm}$ deeper than the first recorded cells were classified as being in new M1; any more superficial cells were classified as being in old M1 [threshold of $2.5 \mathrm{~mm}$ based on the reconstructions by Koželj and Baker (2014)]. The antidromic latency of each PTN was also noted.

\section{Results}

A total of 135 motoneurons were recorded from six monkeys (16 motoneurons projected to upper arm extensors, 75 to forearm flexor muscles, 35 to forearm extensors, and 9 to intrinsic hand muscles). All conduction velocities fell within the expected range (Cheney and Preston, 1976) for primate $\alpha$ and $\beta$ motoneurons rather than $\gamma$ motoneurons (Fig. $1 B$; range, $43.8-95.2 \mathrm{~m} / \mathrm{s}$ ).

\section{Spinal cord volleys from cortical stimulation}

Stimulation through the cortical electrodes produced complex volleys on the spinal cord surface (Fig. $1 C$ ), usually consisting of one direct response ( $\mathrm{D}$ wave) and multiple indirect responses (I waves). Table 1 presents data on the frequency with which D and I waves were elicited from each area, and the mean D and I wave amplitude from each area when seen. Area 3 a electrodes were least likely to generate any observable volley. Both D and I1 wave volleys from new M1 were clear; whereas I1 had a comparable amplitude, the D waves appeared smaller from old M1 compared with new M1, although this difference was not significant, possi- bly attributable to the small dataset (Kruskal-Wallis, $p>0.05$ ). D and I1 waves from the border region and area $3 \mathrm{a}$ were smaller than from either division of M1; this difference reached significance comparing I1 waves from old M1 and the border region (Kruskal-Wallis, $p<0.05$ ).

\section{Classification of postsynaptic responses in motoneurons after cortical stimulation}

Postsynaptic responses to cortical stimulation were identified from averaged intracellular sweeps. For stimulus trains, only the response to the final stimulus was measured by subtracting the average response to one fewer stimuli (e.g., for two stimuli, the average response to one stimulus was subtracted, and for three stimuli, the average response to two stimuli was subtracted; Fig. 2A). Responses were classified as excitatory or inhibitory. The amplitude and absolute (poststimulus) latency of the responses were calculated. This latency was then corrected by subtraction of the D-wave latency, yielding the segmental latency.

We wanted to classify EPSPs further as monosynaptic or polysynaptic in origin. The definitive criterion for classification of a monosynaptic response is that it should have a latency $<1.2 \mathrm{~ms}$ from the $\mathrm{D}$ wave in the cord dorsum response (Riddle et al., 2009), which is also less than the segmental latency of undoubtedly disynaptic IPSPs generated in motoneurons from CST (1.2 ms; Jankowska et al., 1976), primary spindle afferents (1.2 ms; Fetz et al., 1979), and group II muscle afferents (1.4 ms; Edgley and Jankowska, 1987). The cord dorsum volley reflects the fastest fibers in the population of corticospinal axons. However, the corticospinal tract has a large proportion of slow fibers; axons contributing to the overt volley on the cord surface probably make up $<1 \%$ of the tract (Firmin et al., 2014).

If an EPSP is generated solely by slower fibers, or if it arises from fibers participating in an I wave, the latency relative to the $D$ wave could exceed $1.2 \mathrm{~ms}$ even if mediated monosynaptically within the cord. A second criterion that can distinguish monosynaptic versus polysynaptic EPSPs is how the amplitude and timing of the rising phase changes with multiple shocks. If there were interposed interneurons, we reasoned that the first shock would recruit a subset of these cells but bring a further proportion closer to threshold without actually firing them. The second stimulus would be capable of recruiting these cells, leading to augmentation of the second response relative to the first. However, this measure can be complicated by the limited augmentation that occurs even for monosynaptic corticospinal EPSPs because of the properties of the cortico-motoneuronal synapse (Porter and Muir, 1971). We also expected that the second shock would recruit the depolarized interneurons slightly earlier, leading to a reduction in response onset latency. By contrast, monosynaptic effects should show only minimal augmentation and latency shortening with successive stimuli.

We therefore took a multiple-stage approach to classification of EPSPs in this study. The facilitation ratio between the ampli- 
A

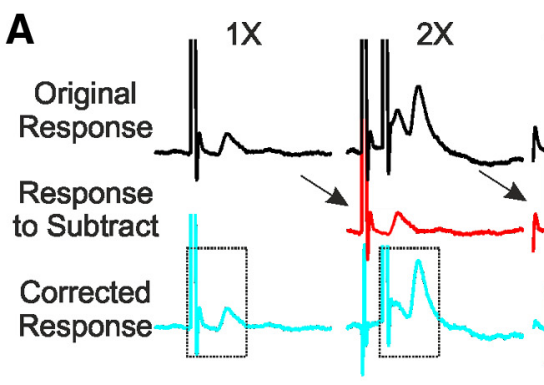

C

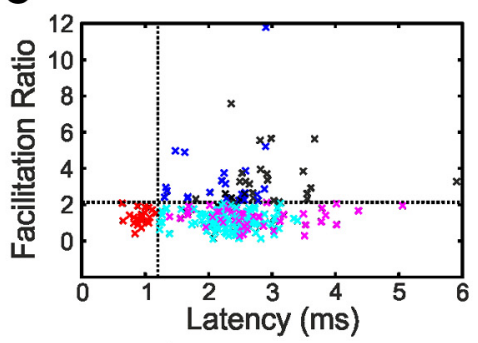

D

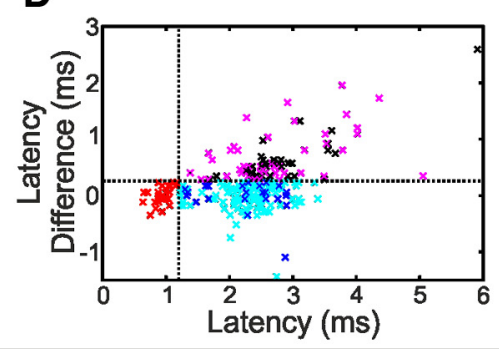

B

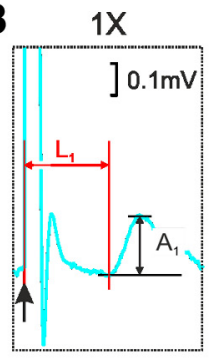

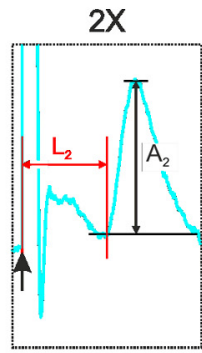

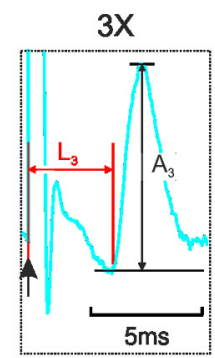

E

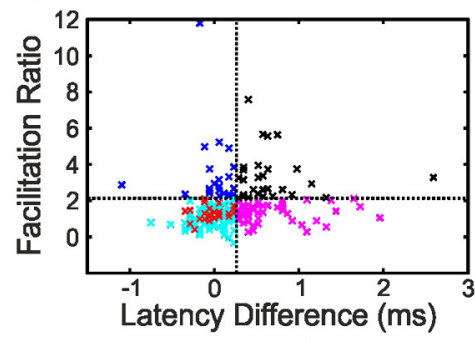

$x$ Monosynaptic $(n=27)$

$\times$ Long-latency monosynaptic $(n=108)$

$\times$ Rejected because of large latency difference only $(n=54)$ $\times$ Rejected because of large latency difference and high facilitation ratio $(n=31)$

$\mathbf{F}$

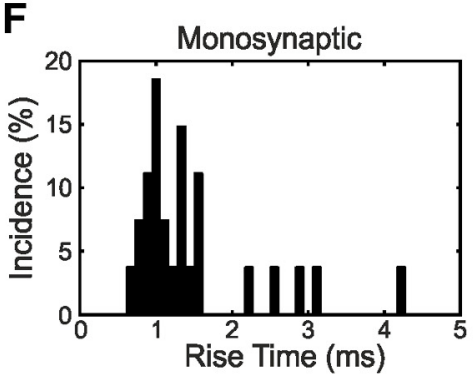

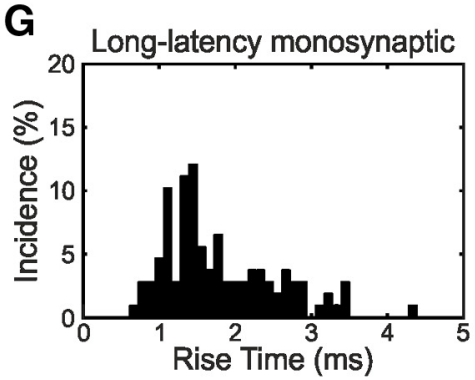

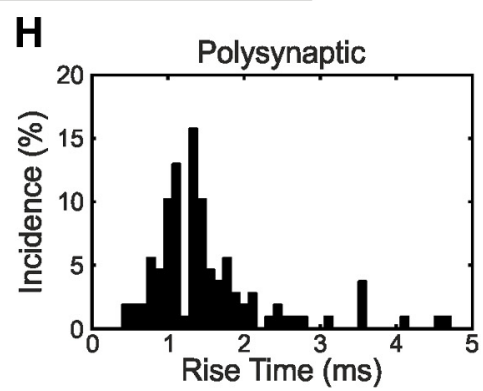

Figure 2. Identifying monosynaptic EPSPs. $A$, The responses to the second and third stimuli (bottom row) were estimated by subtracting the average response to one or two shocks (middle row) from the response to two or three shocks (top row). $\boldsymbol{B}$, Magnified plots of the bottom row in $\boldsymbol{A}$ showing measurements of amplitude $\left(A_{1}-A_{3}\right)$ and latency $\left(L_{1}-L_{3}\right)$. $C$, Plot of facilitation ratio $\left(A_{2} / A_{1}\right)$ versus response latency. Dotted lines represent the first stage of classification of responses into monosynaptic, longer-latency monosynaptic, and polysynaptic EPSPs (vertical line, $1.2 \mathrm{~ms}$; horizontal line, mean facilitation ratio of monosynaptic EPSPs $+2 S D)$. D, Plot of latency difference $\left(L_{1}-L_{3}\right)$ versus response latency. Dotted lines represent the second stage of classification of responses into monosynaptic, longer-latency monosynaptic, and polysynaptic EPSPs (vertical line, $1.2 \mathrm{~ms}$; horizontal line, mean latency difference of monosynaptic EPSPS + 2SD). E, Plot of facilitation ratio versus latency difference. Dotted lines represent classification of responses (vertical line, mean latency difference of monosynaptic EPSPS + 2SD; horizontal line, mean facilitation ratio of monosynaptic EPSPs + 2SD). $\boldsymbol{F}-\boldsymbol{H}$, Histograms of rise times (time to peak amplitude) for EPSPs classified as short-latency monosynaptic, putative long-latency monosynaptic, and polysynaptic, respectively.

tude of the rising phase of the EPSP to one shock $\left(A_{1}\right)$ and the amplitude of the response to the second shock $\left(A_{2}\right)$ was calculated as follows:

$$
\text { Facilitation ratio }=A_{2} / A_{1}
$$

$A_{1}$ and $A_{2}$ were measured as shown in Figure $2 B$. This ratio was then plotted against latency relative to D-wave onset (Fig. $2 B$ ). First, we classified all responses with latency $<1.2 \mathrm{~ms}$ as monosynaptic (Fig. 2C, red crosses). For these EPSPs, we found the mean and SD of the facilitation ratio and set a threshold of mean $+2 \mathrm{SD}$ (Fig. $2 C$, horizontal dotted line; actual value, 2.141). Responses that had a latency of longer than $1.2 \mathrm{~ms}$ and a facilitation ratio greater than this threshold were classified as polysynaptic responses (Fig. 2C, black and blue crosses). For the responses with a latency $>1.2 \mathrm{~ms}$ and a facilitation ratio less than the threshold (Fig. 2C, cyan and magenta crosses), a further classification stage was used. The difference in onset latency between the responses to one stimulus (Fig. 2B, L1) and the third of a train of three (Fig. 2B, L3) was calculated as L1-L3 (a positive value indicating that the response to the third stimulus was earlier, "advancing" compared with the response to one shock). This was plotted against latency relative to D-wave onset (Fig. 2D). As with the facilitation ratio, we took the definitive monosynaptic EPSPs (red crosses), found the mean and SD of the latency difference, and set a threshold of mean +2 SD (Fig. $2 D$, horizontal dotted line; actual value, $0.261 \mathrm{~ms}$ ). All of the potential long-latency monosynaptic effects from Figure $2 C$ were divided into putative long-latency monosynaptic effects if they fell below the threshold (Fig. 2C, cyan crosses) and polysynaptic effects if they exceeded this threshold (Fig. $2 C$, magenta crosses). Figure $2 E$ shows all the effects plotted as facilitation ratio against latency difference with the short-latency monosynaptic effects in red, the putative long-latency monosynaptic effects in cyan, and the polysynaptic effects in black, magenta, or blue. Overall, 27 EPSPs were classified as short-latency monosynaptic, 108 as putative long-latency monosynaptic, and 108 as polysynaptic. A $\chi^{2}$ test (with categories high and low facilitation ratio and small and large latency difference) rejected the null hypothesis that the different classification categories in Figure 

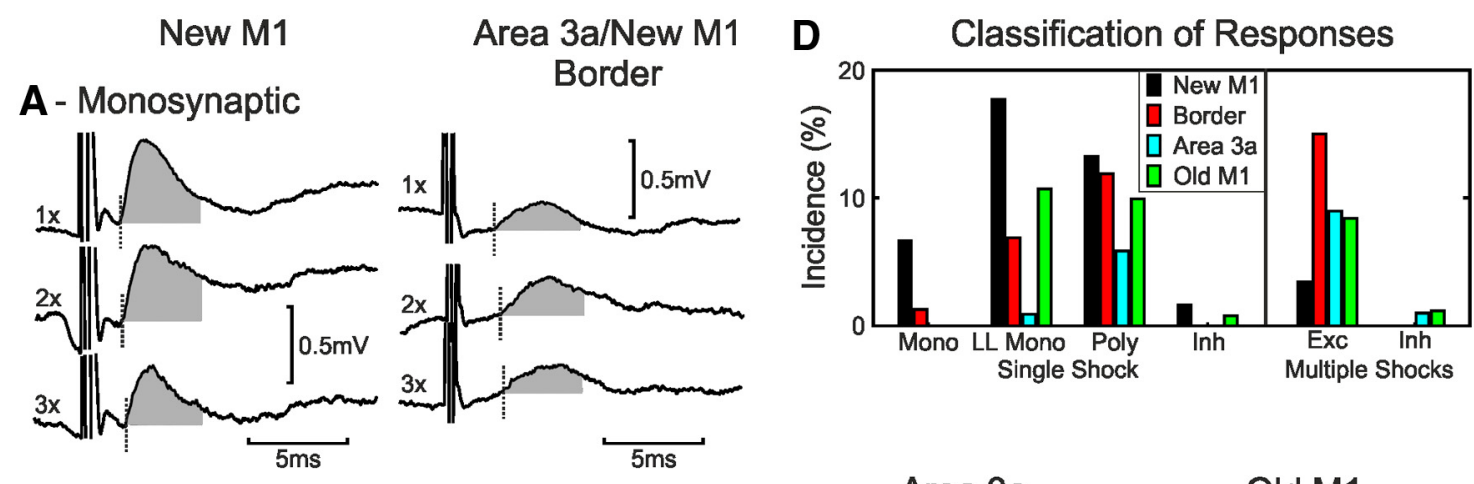

\section{B - Long Latency Monosynaptic}
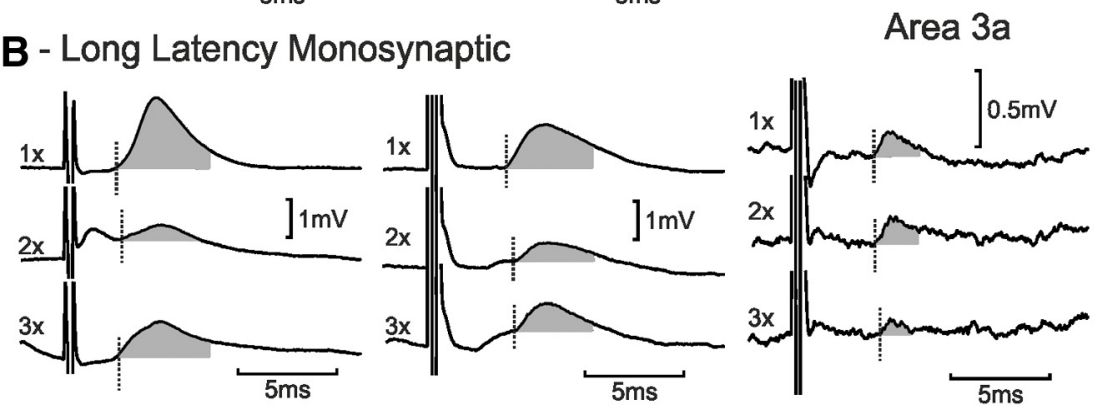

Old M1
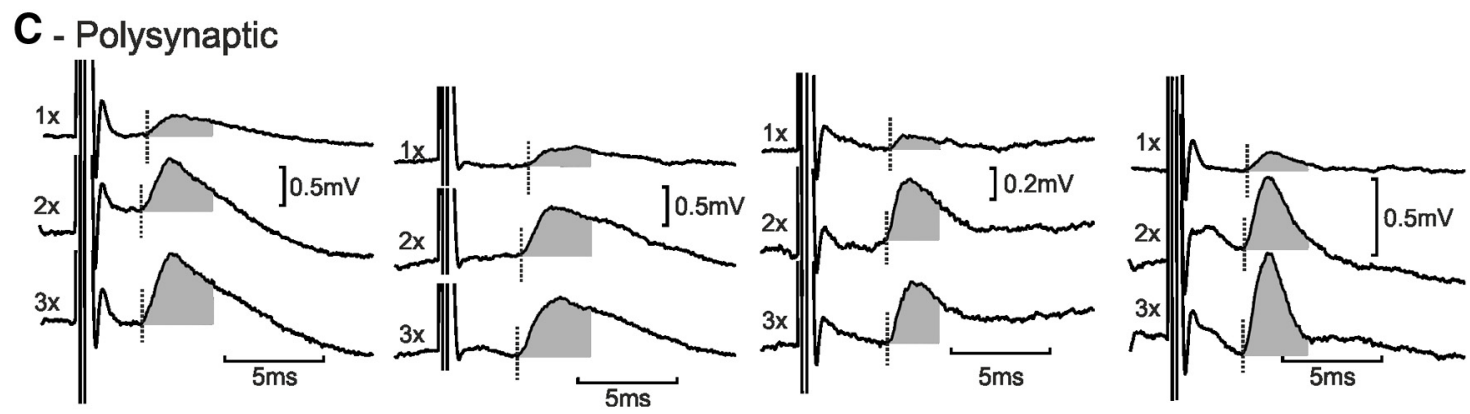

Figure 3. Individual responses to cortical stimulation. Each column shows examples from stimulating electrodes in different cortical areas (from left to right: new M1, border of M1/area 3a, area 3a, and old M1). A, Monosynaptic responses to one, two, and three shocks of new M1 (monkey D, forearm extensor motoneuron) and border (monkey E, forearm flexor) cortical stimulation. See Figure $2 A$ for calculation of responses to one, two, and three shocks. $B$, Examples of putative long-latency monosynaptic EPSPs are shown for stimulation electrodes in new $M 1$ (monkey $E$, forearm flexor), border region (monkey H, forearm flexor), area 3a (monkey D, forearm flexor), and old M1 (monkey B, forearm extensor). C, Examples of polysynaptic EPSPs are shown for stimulation electrodes in new M1 (monkey C, forearm flexor), border region (monkey H, forearm extensor), area 3a (monkey D, intrinsic hand muscle), and old M1 (monkey C, forearm flexor). D, Motoneuron response classification for each cortical area. Mono, Monosynaptic; LL Mono, long-latency monosynaptic; Poly, polysynaptic; Inh, inhibition; Exc, excitation.

$2 E$ were independent, suggesting that this procedure reflected a genuine underlying structure in the data rather than merely arbitrary thresholding of unimodal distributions.

Note that these three classifications have different levels of certainty. It is highly likely that all of the "monosynaptic" EPSPs were indeed mediated by just a single synaptic linkage. By contrast, the evidence for the other two categories is weaker. It is likely that many of the population of "putative long-latency monosynaptic" effects were mediated by one synapse, but we cannot exclude that some of them were generated via synaptic relays. Figure $2 \mathrm{~F}-\mathrm{H}$ show the rise times (time from EPSP onset to EPSP peak amplitude) for the three classifications. Putative longlatency monosynaptic EPSPs had significantly longer rise times than both short-latency monosynaptic EPSPs and polysynaptic EPSPs ( $p<0.01$, Kruskal-Wallis test). Slower rise times can be indicative of activation more distally on the dendrites (Jack et al., 1971). However, caution should be taken when interpreting these rise times as many of the synaptic responses were complex, with IPSPs occurring superimposed on the EPSP. This would shorten the apparent rise time.
Characteristics of synaptic responses to cortical stimulation As well as classifying responses based on the likely number of interposed synapses, we also separated cortical electrodes into four categories: old M1, new M1, area 3a/new M1 border, and area $3 \mathrm{a}$.

Figure $3 A$ shows monosynaptic EPSPs evoked in one forearm extensor motoneuron recorded from monkey $\mathrm{D}$ in response to stimulation of a new M1 electrode (left) and in one forearm flexor motoneuron recorded from monkey $\mathrm{E}$ in response to stimulation of a border electrode (right). The segmental latencies of the effects were 0.88 and $0.75 \mathrm{~ms}$, respectively, confirming them as unambiguously mediated by a monosynaptic linkage. Both electrodes were in the cortical hand representation. Figure $3, B$ and $C$, show examples of longer-latency EPSPs that were classified as long-latency monosynaptic (Fig. 3B) and polysynaptic (Fig. 3C) according to the methods in Figure 2. Although we could find examples of long-latency monosynaptic and polysynaptic responses from stimulation of each category of the cortical electrode site, short-latency monosynaptic responses were only seen from new M1 and the 3a/new M1 border region. 

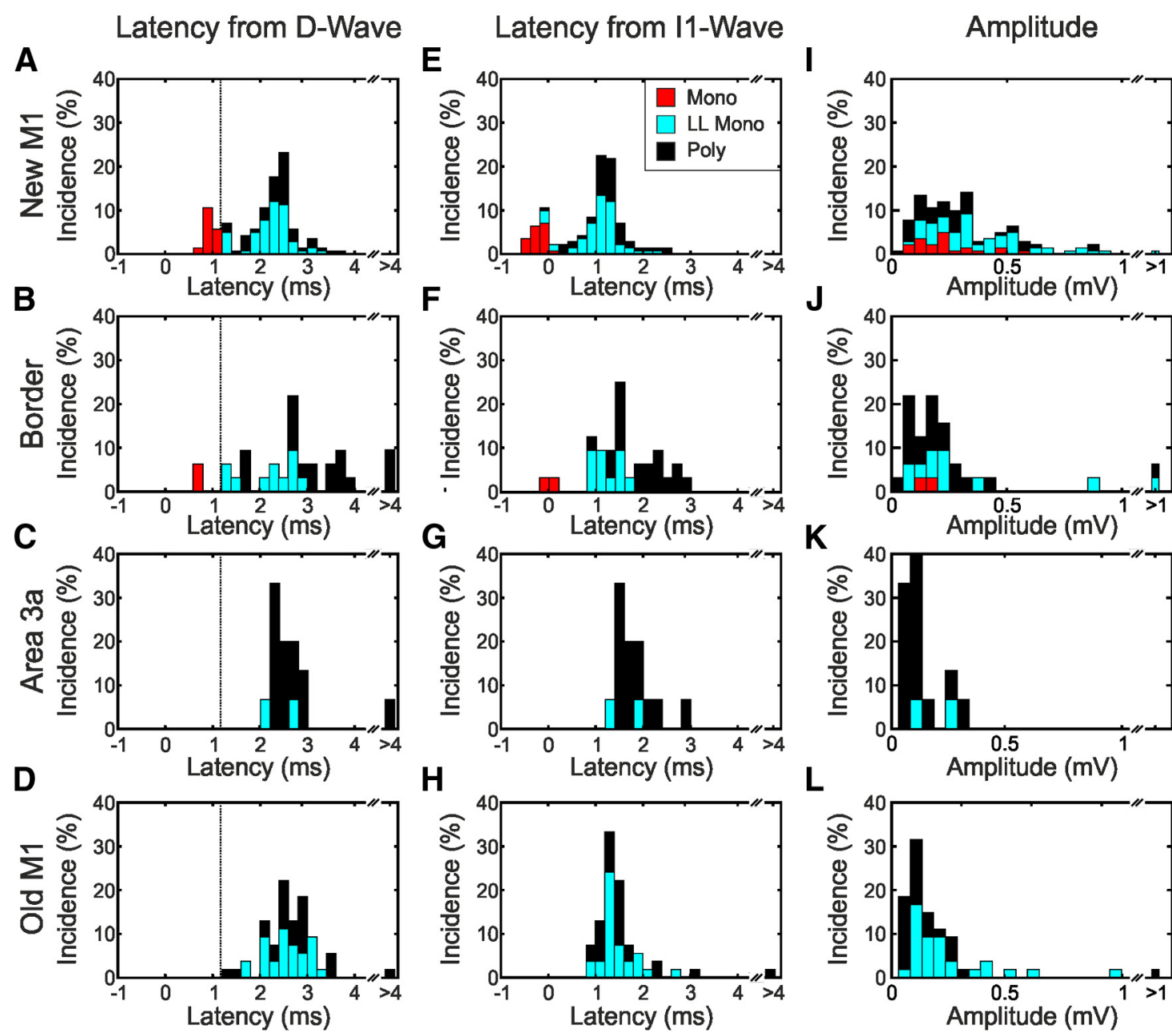
M1, border, area 3a, and old M1 cortical stimulation, respectively. $\boldsymbol{E}-\boldsymbol{H}$, Histograms of EPSP latency measured relative to I1-wave latency for responses to new M1, border, area 3a, and old M1 cortical stimulation, respectively. I-L, Amplitude of EPSP responses to new M1, border, area 3a, and old M1 cortical stimulation, respectively. Mono, Monosynaptic; LL Mono, long-latency monosynaptic; Poly, polysynaptic.

Figure $3 D$ shows the incidence of the different types of postsynaptic potentials elicited from each cortical region. New M1 had the highest incidence of EPSPs to single stimuli across all three categories of responses (monosynaptic, putative longlatency monosynaptic, and polysynaptic). Area 3a had the lowest incidence of responses across the same three categories. Only new M1 and old M1 sites elicited pure IPSPs to a single shock (without an earlier excitatory component), but this was rare, accounting for only $0.8 \%$ of responses. Polysynaptic EPSPs were common to multiple shocks of stimulation to old M1, the border region, and area $3 \mathrm{a}$.

\section{Latency and amplitude of EPSPs}

The EPSP latencies were calculated relative to the onset latency of the segmental D waves (Fig. 4A-D) and I1 waves (Fig. 4E, F) and are shown for each cortical area. Only EPSPs elicited by a single shock were analyzed for Figure 4, and latencies are shown for responses classified as monosynaptic (Mono), putative longlatency monosynaptic (LL Mono), and polysynaptic (Poly) EPSPs. For new M1, there was a bimodal distribution with the first peak clustered around $1 \mathrm{~ms}$ after the $\mathrm{D}$ wave (Fig. $4 \mathrm{~A}$ ) and the second peak clustered around $1 \mathrm{~ms}$ after the I1 wave (Fig. 4E). For the other three cortical sites, the distribution was more unimodal and clustered around $1 \mathrm{~ms}$ after the I1 wave (Fig. $4 F-H$ ). EPSPs classified as polysynaptic occurred at similar latencies to the putative long-latency monosynaptic responses. Combining across all areas, the SD of putative long-latency monosynaptic segmental latencies was $0.47 \mathrm{~ms}$ when aligned to the $\mathrm{D}$ wave and $0.46 \mathrm{~ms}$ when aligned to the I1 wave. This population variance was significantly smaller than for the EPSPs classified as polysynaptic $(0.73$ $\mathrm{ms}$ aligned to the $\mathrm{D}$ wave, $0.65 \mathrm{~ms}$ aligned to the I1 wave; twosample $F$ test for equal variances, $p<0.001$ for comparison with putative long-latency monosynaptic in both cases).

The EPSP amplitudes are shown in Figure $4 I-L$ for each cortical area and EPSP type. The distributions for old M1, area 3a, and the border zone are heavily skewed toward low amplitudes. Putative long-latency monosynaptic EPSPs elicited by new M1 were larger in amplitude than those from old M1, and polysynaptic EPSPs elicited by new M1 were larger in amplitude than those from old M1 and area 3a $(p<0.05$, Kruskal-Wallis test; Bonferroni's correction for multiple comparisons). There was no significant difference in the amplitude of monosynaptic EPSPs elicited from new M1 and the border region. Median and SE values for EPSP amplitudes are given in Table 2.

To generate an overall estimate of the overall importance of the three categories of EPSP from each cortical region, we calcu- 
Table 2. Median amplitude of EPSPs

\begin{tabular}{llll}
\hline & $\begin{array}{l}\text { Monosynaptic } \\
\text { EPSP }\end{array}$ & $\begin{array}{l}\text { Putative long-latency } \\
\text { monosynaptic EPSP }\end{array}$ & Polysynaptic EPSP \\
\hline New M1 & $214.9 \pm 31.9 \mu \mathrm{V}$ & $340.8 \pm 50.0 \mu \mathrm{V}$ & $247.2 \pm 49.6 \mu \mathrm{V}$ \\
Border region & $173.6 \pm 31.2 \mu \mathrm{V}$ & $212.0 \pm 119.4 \mu \mathrm{V}$ & $173.0 \pm 86.2 \mu \mathrm{V}$ \\
Area 3a & Not found & $197.5 \pm 88.9 \mu \mathrm{V}$ & $110.2 \pm 28.8 \mu \mathrm{V}$ \\
Old M1 & Not found & $184.1 \pm 46.6 \mu \mathrm{V}$ & $111.7 \pm 49.6 \mu \mathrm{V}$ \\
\hline
\end{tabular}

All values are given as median \pm SE of median.

Table 3. Values of amplitude $\times$ incidence for effects in different categories, from each cortical area

\begin{tabular}{lllll}
\hline & & Putative long-latency & & \\
& Monosynaptic EPSP & monosynaptic EPSP & Polysynaptic EPSP & Total \\
\hline New M1 & $15.3 \pm 6.1 \mu \mathrm{V}$ & $78.1 \pm 20.5 \mu \mathrm{V}$ & $36.5 \pm 11.5 \mu \mathrm{V}$ & $129.9 \mu \mathrm{V}$ \\
& $12 \%$ & $60 \%$ & $28 \%$ & $100 \%$ \\
Border region & $2.2 \pm 1.2 \mu \mathrm{V}$ & $21.8 \pm 15.1 \mu \mathrm{V}$ & $28.3 \pm 15.7 \mu \mathrm{V}$ & $52.3 \mu \mathrm{V}$ \\
& $4 \%$ & $42 \%$ & $54 \%$ & $100 \%$ \\
Area 3a & $0 \mu \mathrm{V}$ & $1.8 \pm 1.2 \mu \mathrm{V}$ & $7.9 \pm 4.3 \mu \mathrm{V}$ & $9.7 \mu \mathrm{V}$ \\
& $0 \%$ & $19 \%$ & $81 \%$ & $100 \%$ \\
Old M1 & $0 \mu \mathrm{V}$ & $26.7 \pm 11.2 \mu \mathrm{V}$ & $17.7 \pm 8.4 \mu \mathrm{V}$ & $44.4 \mu \mathrm{V}$ \\
& $0 \%$ & $60 \%$ & $40 \%$ & $100 \%$
\end{tabular}

Error estimates are SEs, determined using the Monte Carlo resampling procedure described by Zaaimi et al. (2012). Percentages show the percentage of total input from a given cortical area in each category.

lated the amplitude $\times$ incidence; this is equivalent to finding the mean EPSP amplitude, including (as zeros) those sites that did not produce an effect (Zaaimi et al., 2012). These values are given in Table 3; percentages list the proportion of output from one area that was mediated by a given synaptic linkage. These values must be treated with caution. Anesthesia is likely to reduce the amplitude of polysynaptic effects by reducing the excitability of the interposed interneurons, and superimposed IPSPs are likely to have reduced apparent EPSP amplitudes. However, this table provides a useful summary of the relative importance of the different outputs to motoneurons as measured in our study.

\section{Effect of muscle group innervated by motoneuron}

Motoneurons were classified into four groups according to which nerves they could be antidromically activated from: upper arm extensors (radial nerve at the axilla but not deep radial), forearm flexors (median and ulnar nerve at the arm but not the wrist), forearm extensors (deep radial nerve), and intrinsic hand muscles (median and ulnar nerve at the wrist). The incidence of each type of EPSP response, amplitude of EPSP responses, and the amplitude $X$ incidence in these different groups are shown in Figure 5. Upper arm extensors showed the lowest incidence of EPSPs after stimulation of any of the four cortical areas (11.3\% of all single stimuli elicited EPSPs in upper arm extensors compared with $25.4 \%$ in forearm flexors, $22.6 \%$ in forearm extensors, and $35.8 \%$ in intrinsic hand muscles; $\chi^{2}$ test, $p<0.01$ ). The EPSP amplitude after new M1 stimuli was also slightly lower for upper arm extensors across the three EPSP types, but this was not significant (Kruskal-Wallis test, $p>0.05$ ). Intrinsic hand muscles showed the highest incidence of fast monosynaptic EPSPs after new M1 stimuli, as might be expected from the known distal bias of the corticospinal pathway (Fritz et al., 1985). Note that this incidence does not relate to the overall proportion of forearm motoneurons with corticospinal tract connections, but reflects only the subset of inputs activated by the intracortical stimulus.

\section{Conditioning of new M1 stimuli}

Polysynaptic EPSPs from old M1, area 3a, and the border region could be mediated by several candidate pathways. The simplest
A
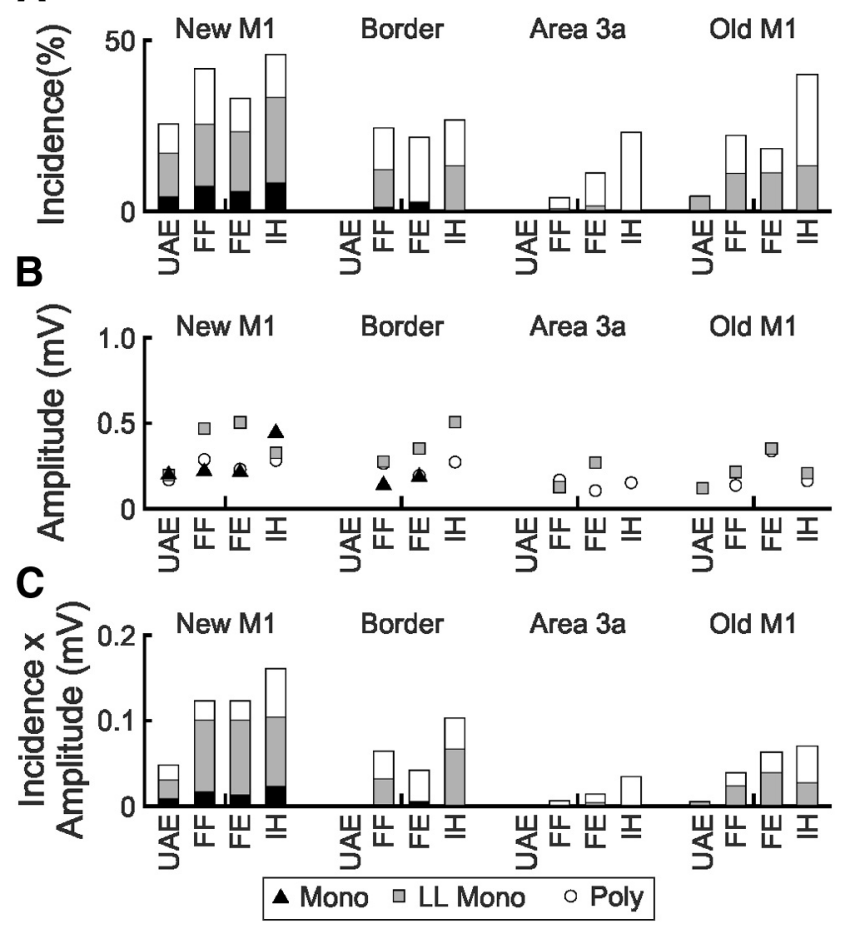

Figure 5. Incidence and amplitude of EPSPs grouped by motoneuron innervation target. $\boldsymbol{A}$, Incidence of monosynaptic, long-latency monosynaptic, and polysynaptic EPSPs in motoneurons grouped according to projection target occurring in response to stimulation of new M1, area 3a/new M1 border, area 3a, and old M1 cortical sites. $\boldsymbol{B}$, Mean amplitude of EPSPs in $\boldsymbol{A}$. $\boldsymbol{C}$, Amplitude $X$ incidence of EPSPs in $A$. UAE, Upper arm extensors; FF, forearm flexors; FE, forearm extensors; IH, intrinsic hand muscles; Mono, monosynaptic; LL Mono, long-latency monosynaptic; Poly, polysynaptic.

routes for disynaptic coupling would involve either (1) direct activation of local corticospinal outputs followed by transsynaptic activation of segmental or propriospinal premotor interneurons in the spinal cord (Alstermark et al., 1999; Riddle and Baker, 2010; Takei and Seki, 2010) or (2) direct activation of corticocortical connections to new M1 followed by transsynaptic activation of corticospinal neurons with monosynaptic connections to motoneurons (Shimazu et al., 2004). We tested for the latter possibility using a conditioning paradigm.

Motoneurons were chosen for conditioning if they responded with a monosynaptic EPSP after stimulation of new M1. The new M1 stimulus was then conditioned by prior stimulation of an electrode in old M1, area 3a, or the border zone, with interstimulus intervals between 1 and $9 \mathrm{~ms}$. We reasoned that if some of the response from the conditioning electrode was mediated by cells at the new M1 site, we would see changes in the monosynaptic new M1 response when conditioned. Only a small number of motoneuron recordings were stable enough to permit this experiment. The conditioning electrode produced a putative longlatency monosynaptic response $(n=6)$, polysynaptic response $(n=5)$, or no significant response $(n=5)$ when stimulated alone. We compared the actual conditioned response to what we would expect from a linear summation of the responses produced by test and conditioning stimuli alone using a Monte Carlo resampling procedure (see Materials and Methods).

Figure $6 \mathrm{~A}$ shows an example recording from a single motoneuron. In this case, the conditioning stimulus was given to old M1, and when delivered alone, it produced a putative long-latency monosynaptic response. The overlain traces 
A

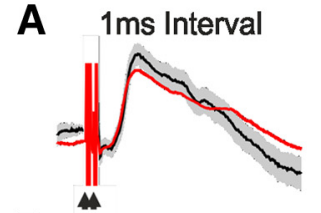

B

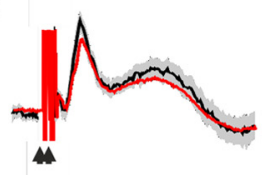

$3 m s$ Interval
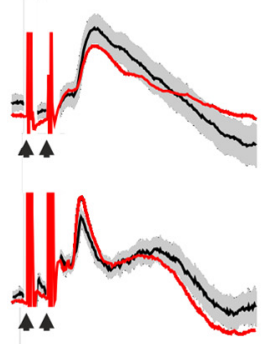

$5 \mathrm{~ms}$ Interval
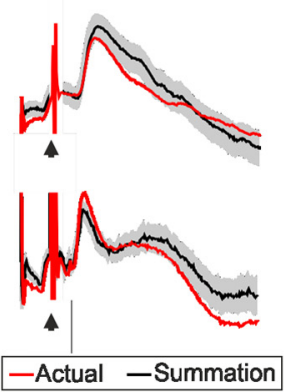
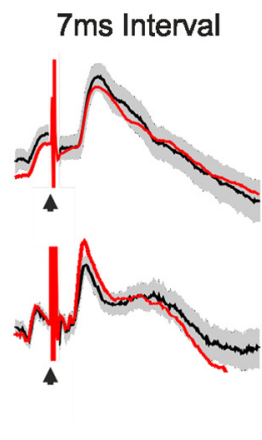
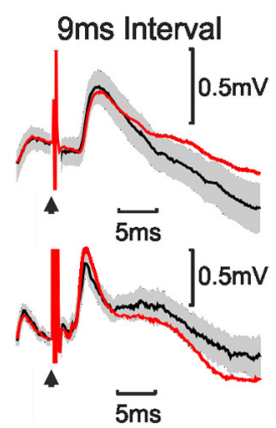
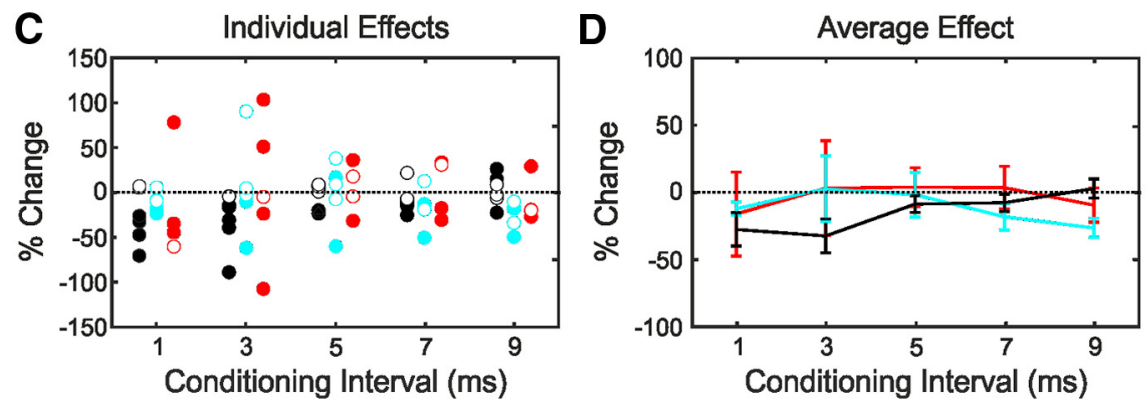

Figure 6. Effect of conditioning of new M1 stimulus by other cortical stimuli on EPSP amplitude. A, Average EPSPs in response to new M1 stimulation conditioned by old M1 stimulation at five different intervals, showing suppression of the EPSP. The average response to the conditioned stimulus is shown in red together with the expected response from summation of the responses to the test stimulus alone and the conditioning stimulus alone (black). The shaded area represents $95 \%$ confidence intervals on expected response. $\boldsymbol{B}$, As in $\boldsymbol{A}$, but for a different motoneuron. Shown are the average EPSPs in response to new M1 stimulation conditioned by area 3a stimulation, showing facilitation of the EPSP. C, Conditioned EPSP amplitude as a percentage of the expected EPSP amplitude from summation for all conditioning intervals. Filled circles indicate responses significantly different from expected. $\boldsymbol{D}$, Average percentage response change as a function of the interstimulus interval. Error bars show SEM. Results in $\boldsymbol{C}$ and $\boldsymbol{D}$ have been averaged across cortical areas. LL, Long latency.

show average responses for the combined stimuli (red) and the linear sum of responses to new M1 and conditioning stimulus when given alone (black; with 95\% confidence intervals in gray). Five different interstimulus intervals are illustrated in the different columns of Figure 6A. For this example, the monosynaptic response from new M1 was smaller than expected at intervals of 1 and $3 \mathrm{~ms}$ (compare red trace with the gray shaded area). A second example is shown in Figure $6 B$ for a conditioning electrode in area 3 a that produced a polysynaptic response when given alone. In this case, the monosynaptic response from new M1 was increased by the conditioning stimulus for all but the shortest interval tested.

Figure $6 C$ shows the percentage change in amplitude of individual responses, measured as described in Materials and Methods so that negative values indicate suppression and positive values facilitation. Filled symbols mark changes that were individually significant; the color of the points indicates the nature of the response from the conditioning electrode alone. Because of the small numbers of recordings available, results from old $\mathrm{M} 1$, area $3 \mathrm{a}$, and the border region conditioning electrodes have been combined in Figure 6C. When the conditioning electrode generated putative long-latency monosynaptic or no response when stimulated alone, in almost all cases its effect on the new M1 monosynaptic response was suppression. By contrast, when the conditioning electrode generated polysynaptic responses when stimulated alone, the effects on the new M1 monosynaptic response were a mixture of suppression and facilitation. All significant facilitations seen in this case were generated in the same motoneuron, from two different area 3 a stimulating electrodes.

Figure $6 D$ shows the average change at a given interstimulus interval and conditioning response category; error bars represent the SEM. None of the average effects in Figure $6 D$ were signifi- cantly different from zero ( $t$ test, $p<0.05$ with Bonferroni's correction for multiple comparisons), possibly reflecting the limited size of the dataset.

\section{Pyramidal tract neuron conduction velocity}

A major finding of this study is that old M1 appears to produce monosynaptic input to motoneurons over more slowly conducting fibers than new M1. It was, therefore, of interest to compare the conduction velocities of PTNs in the two M1 subdivisions, using an extensive dataset compiled from our previous work. Over 10 animals, recordings from 641 PTNs were available, of which 297 cells were classified as being in new M1 and 344 cells in old M1 based on the recording depth (see Materials and Methods). Figure 7A presents the distribution of the antidromic latencies as cumulative probability curves; the distribution is clearly shifted toward slower latencies for old M1 (mean antidromic latency of 1.33 and $1.53 \mathrm{~ms}$ for new M1 and old M1, respectively; $p<2 \times 10^{-4}$, Wilcoxon test). These latencies were converted to conduction velocities using an estimated conduction distance of $47 \mathrm{~mm}$ (Humphrey and Corrie, 1978; Firmin et al., 2014); the distribution of conduction velocities is shown in Figure $7 B$.

It is well known that extracellular recordings exhibit a recording bias, with larger cells (having faster conducting axons) being over-represented (Firmin et al., 2014). Humphrey and Corrie (1978) proposed a means to correct for this bias by multiplying the observed fraction of cells at a given velocity $v$ by $v^{-3 / 2}$, although even this does not account for the failure to observe very slowly conducting fibers (Firmin et al., 2014). Figure 7C presents the distributions corrected using this approach. The estimated mean conduction velocity was $30.4 \mathrm{~m} / \mathrm{s}$ for new M1 compared with $26.3 \mathrm{~m} / \mathrm{s}$ for old M1. 

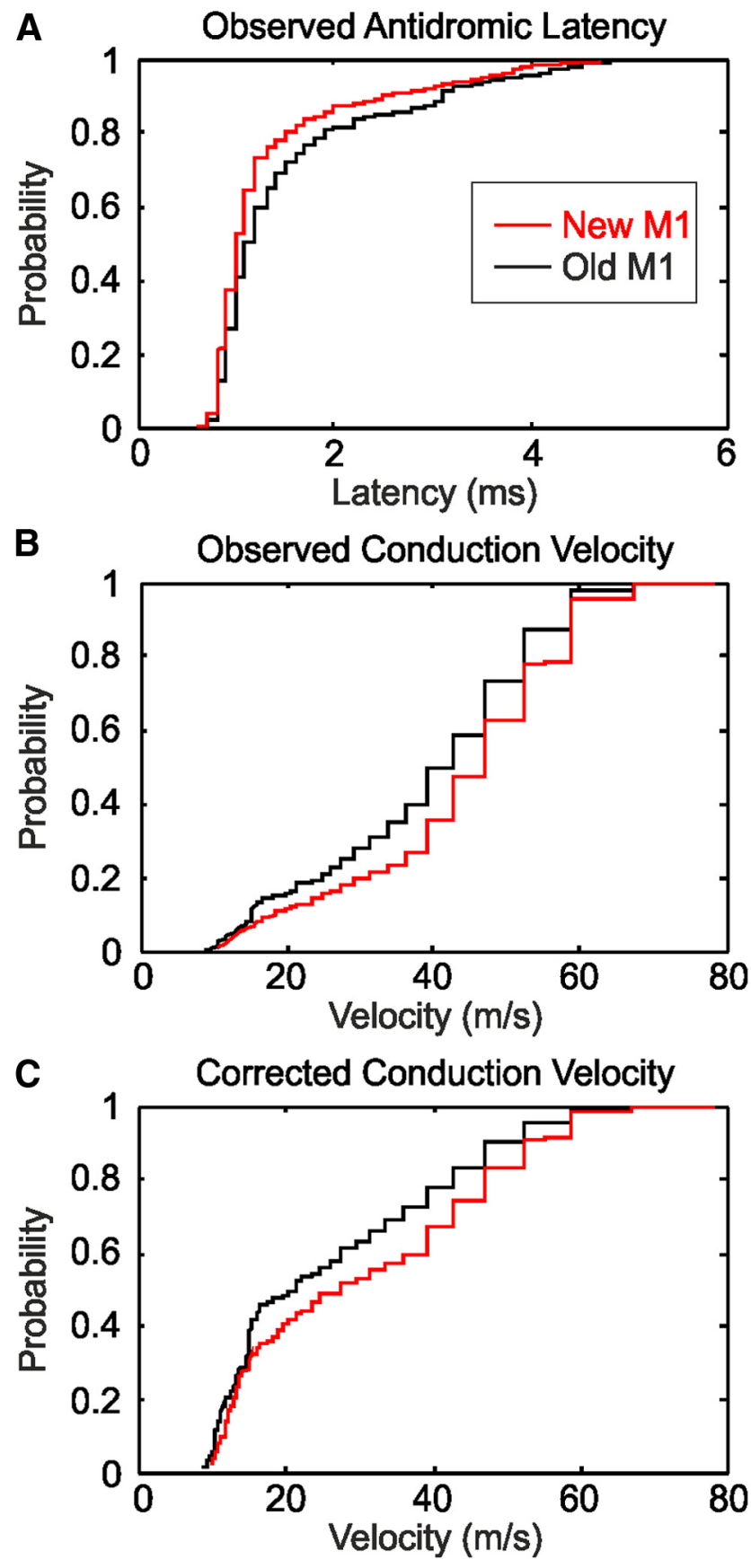

Figure 7. Comparison of the properties of PTNs in new M1 and old M1. $A$, Cumulative probability plot of the antidromic latency after stimulation at the medullary pyramid. $\boldsymbol{B}$, Cumulative probability plot of the conduction velocity, estimated from $\boldsymbol{A}$ using a conduction distance of 47 $\mathrm{mm}$. $\boldsymbol{C}$, as in $\boldsymbol{B}$, but corrected for the sampling bias of extracellular recordings toward large neurons as described in the text.

\section{Discussion}

Determining the likely synaptic basis of later responses

All recordings in this study were made under anesthesia, which could render interneurons inexcitable and prevent the detection of disynaptic effects (Alstermark et al., 1999); the reported relative proportions of monosynaptic and polysynaptic responses must, therefore, be treated with caution. However, if polysynaptic effects were seen at all, there is no reason why anesthesia should prevent the generation of a subliminal fringe by the first shock and subsequent response augmentation and latency shortening after subsequent stimuli. Anesthesia is thus unlikely to have led to the erroneous classification of polysynaptic effects as monosynaptic.

For polysynaptic effects, we cannot determine where the interposed interneuron may lie. If it is within the spinal cord, the location could be either within the same segment as the target motoneurons (Riddle and Baker, 2010) or more rostral at C3-C4 (a propriospinal interneuron; Isa et al., 2006). Another possibility is within the cortex itself: these responses could be mediated by cortico-motoneuronal outputs from new M1 activated via intracortical axons. In this case, the "polysynaptic" EPSPs would be monosynaptic at the segmental level, but in response to the I1 corticospinal volley. We investigated this by conditioning stimuli in new M1 with preceding stimulation of old M1 or area 3a sites. Where the conditioning stimulus generated either a monosynaptic or no response in motoneurons, the effect on the new M1 response tended to be suppression, presumably reflecting a diffuse tendency for inhibition comparable to the "short-interval intracortical inhibition" reported for pairs of transcranial magnetic stimuli (Kujirai et al., 1993). When the conditioning stimulus generated a polysynaptic response in motoneurons, some instances of facilitation were seen (Fig. 6C). This is consistent with at least part of the polysynaptic responses passing via new $\mathrm{M} 1$; this is similar to previous findings in premotor area F5 (Shimazu et al., 2004).

\section{Relation to previous work}

Outputs from new M1 and area 3a were very different: area 3a yielded few monosynaptic responses, whereas new M1 stimulation generated many fast and long-latency monosynaptic effects. Electrodes at the area $3 \mathrm{a} / \mathrm{M} 1$ border gave intermediate effects. This may reflect a genuine transition zone with outputs reflecting aspects of both new M1 and 3a organization. However, the stimulus used $(300 \mu \mathrm{A})$ will excite cells up to $0.5 \mathrm{~mm}$ from the electrode tip [Stoney et al. (1968), formula in their Fig. 8]. Current spread from border zone sites probably, therefore, led to simultaneous activation of both areas.

The average conduction velocity is higher for corticospinal axons from M1 than from nonprimary motor (Firmin et al., 2014) or somatosensory (Widener and Cheney, 1997; Witham and Baker, 2007) cortex. The largest corticospinal neurons in M1 are bigger than in somatosensory cortex (Murray and Coulter, 1981; Rathelot and Strick, 2006), also agreeing with faster output from M1. The dearth of fast corticospinal axons leaving area 3a would explain why we saw no fast monosynaptic effects after stimulation. The smaller D-wave volley elicited from old M1 compared with new M1 stimulation (Table 1) is consistent with fewer of the fastest corticospinal axons originating in old M1, which we confirmed in a large dataset of antidromically activated PTNs (Fig. 7). There was, however, considerable overlap between old M1 and new M1 PTN conduction velocities. The lack of fast monosynaptic effects from old M1 probably, therefore, reflects not just the distribution of axon velocities but also a selective failure of the fastest axons to make cortico-motoneuronal synapses.

Rathelot and Strick (2006, 2009) mapped cortico-motoneuronal cells using retrograde trans-synaptic transport of rabies virus; labeled cells were almost exclusively within new M1 and area 3a. They suggested that CM cells in area 3a may project to fusimotor $(\gamma)$ motoneurons, since intracortical microstimulation within 3a does not reliably generate muscle twitches (although see Wannier et al., 1991; Widener and Cheney, 1997). In our recordings, a monosynaptic EPSP followed area 3a stimulation in only $0.9 \%$ of motoneurons; all such effects were at long 
latency, consistent with the lack of the largest CM cell bodies $(>50 \mu \mathrm{m})$ within area 3a (Rathelot and Strick, 2006). Our results thus agree broadly with the conclusion of Rathelot and Strick $(2006,2009)$ that the majority of CM outflow from 3a does not target $\alpha$ motoneurons.

Although we found no fast monosynaptic effects after stimulation of old M1, putative long-latency monosynaptic potentials were observed (Fig. $3 B, D$ ). By contrast, Rathelot and Strick $(2006,2009)$ found almost no CM cells within old M1. One possible explanation is that the trans-synaptic transport of rabies virus was selective for some feature that distinguished new M1 from old M1 CM cells. It does not seem that such selection could be on the basis of conduction velocity, since Rathelot and Strick (2006) reported a wide range of labeled cell sizes within new M1, consistent with rabies infection of slow as well as fast axons. An alternative possibility is that CM connections from old M1 target distal dendrites of motoneurons and that the rabies virus is less efficient at crossing synapses on these distal extremities. In agreement with this, published micrographs of infected neurons often show rabies labeling in proximal dendrites but do not appear to reveal the entire dendritic tree (Ugolini, 2010). Yoshino-Saito et al. (2010) injected anterograde tracer (BDA) into new M1 or old M1 and found that only new M1 injections labeled significant numbers of corticospinal terminals around the motoneuron cell bodies in lamina IX. Any CM connections from old M1 would, therefore, have to occur on distal motoneuron dendrites outside lamina IX. Although distributions were overlapping, the putative long-latency monosynaptic responses had significantly longer rise times than the short-latency monosynaptic potentials (Fig. $2 F, G)$, which would be consistent with a location more distally on the dendrites (Jack et al., 1971).

This situation is reminiscent of previous work in two species of New World monkey. Although the cebus monkey has corticospinal terminals in lamina IX, the less dexterous squirrel monkey does not (Bortoff and Strick, 1993). A subsequent electrophysiological study found monosynaptic EPSPs in squirrel monkey motoneurons after stimulation of the medullary pyramid (Maier et al., 1997), but these had low amplitude and slow rise time, consistent with mediation via synapses on distal dendrites. In the present work, $78 \%$ of putative long-latency monosynaptic effects from old M1 were smaller than $0.3 \mathrm{mV}$, whereas $63 \%$ of such effects from new M1 were larger than this value. The lower amplitude is compatible with a more distal synaptic location. A comparison of rise times between putative long-latency monosynaptic effects in old M1 and new M1 revealed no significant difference $(1.59 \pm 0.11 \mathrm{~ms}$ vs $1.70 \pm 0.09 \mathrm{~ms} ; p>0.05$, Wilcoxon rank sum test).

\section{Implications for control of primate movements}

An important conclusion of Rathelot and Strick $(2006,2009)$ was that macaque M1 could be divided into two functionally distinct regions, with different access to spinal motoneurons. Other work proposed a similar division of M1 on different criteria (Tanji and Wise, 1981; Strick and Preston, 1982a,b; Geyer et al., 1996). Our results support this notion but qualify it. Rather than old M1 controlling motoneurons only via spinal interneuron relays, we suggest that it does have CM connections. However, these are quantitatively different from those made by new M1, with slower conduction and lower-amplitude EPSPs. Rather than seeing old M1 as the homolog of nonprimate M1 that lacks CM outflow, we see it as comparable to M1 in New World primates such as the squirrel monkey. The evolutionary development of new M1 in Old World monkeys then marks merely the next stage of placing motoneurons under ever more direct control of the cortex, leading to perisomatic corticospinal terminals among the motor nuclei.

While it is tempting to focus on the monosynaptic CM connections, importantly all cortical areas investigated here produced polysynaptic effects in motoneurons. As noted above, these could be mediated via subcortical interneurons or intracortical connections to the fast CM cells of new M1. Our finding of widespread polysynaptic effects after focal stimuli in the cortex contrasts sharply with the lack of non-monosynaptic responses in motoneurons after stimulation of the pyramidal tract at the medulla (Maier et al., 1998; Olivier et al., 2001). Alstermark et al. (1999) suggested that mass stimulation of the whole tract may recruit both excitatory and inhibitory disynaptic circuits, leading to no observable effect. A focal cortical stimulus may, in contrast, excite a functionally homogeneous circuit, producing consistent disynaptic excitation of the target motoneurons. It is known that spinal interneurons at both segmental (Takei and Seki, 2010) and propriospinal (Kinoshita et al., 2012) levels are involved in control of fine hand function and that these receive corticospinal input (Isa et al., 2006; Riddle and Baker, 2010), probably from both old and new M1 (Yoshino-Saito et al., 2010). In addition, reticulospinal cells located in the brainstem receive input from old M1 (Keizer and Kuypers, 1989) and project to motoneurons (Riddle et al., 2009); reticular formation cells also modulate their discharge during fine hand control (Soteropoulos et al., 2012). The relative importance of these outputs versus the slow CM projections from old M1 is unknown.

The diversity of routes by which motor commands can travel from motor areas of the cortex to motoneurons can be exploited after brain lesions, such as occur after a stroke, as it allows the motor system to reconfigure to rely on surviving pathways (Baker et al., 2015). However, in most clinical situations, old M1 and new $\mathrm{M} 1$ are likely to be damaged in tandem (e.g., middle cerebral artery stroke), or their corticospinal outputs interrupted similarly (e.g., in spinal cord injury). Unfortunately, the division between these areas is thus unlikely to provide alternative pathways that could be exploited to aid functional recovery.

\section{References}

Alstermark B, Isa T, Ohki Y, Saito Y (1999) Disynaptic pyramidal excitation in forelimb motoneurons mediated via $\mathrm{C}(3)-\mathrm{C}(4)$ propriospinal neurons in the Macaca fuscata. J Neurophysiol 82:3580-3585. Medline

Baker SN, Philbin N, Spinks R, Pinches EM, Wolpert DM, MacManus DG, Pauluis Q, Lemon RN (1999) Multiple single unit recording in the cortex of monkeys using independently moveable microelectrodes. J Neurosci Methods 94:5-17. CrossRef Medline

Baker SN, Spinks R, Jackson A, Lemon RN (2001) Synchronization in monkey motor cortex during a precision grip task. I. Task-dependent modulation in single-unit synchrony. J Neurophysiol 85:869-885. Medline

Baker SN, Zaaimi B, Fisher KM, Edgley SA, Soteropoulos DS (2015) Pathways mediating functional recovery. Progress Brain Res 218:389-412. CrossRef Medline

Bortoff GA, Strick PL (1993) Corticospinal terminations in two newworld primates: further evidence that corticomotoneuronal connections provide part of the neural substrate for manual dexterity. J Neurosci 13:5105-5118. Medline

Cheney PD, Preston JB (1976) Classification of fusimotor fibers in the primate. J Neurophysiol 39:9-19. Medline

Dum RP, Strick PL (1991) The origin of corticospinal projections from the premotor areas in the frontal lobe. J Neurosci 11:667-689. Medline

Edgley SA, Jankowska E (1987) An interneuronal relay for group I and II muscle afferents in the midlumbar segments of the cat spinal cord. J Physiol 389:647-674. CrossRef Medline

Fetz EE, Jankowska E, Johannisson T, Lipski J (1979) Autogenetic inhibition of motoneurones by impulses in group Ia muscle spindle afferents. J Physiol 293:173-195. CrossRef Medline 
Firmin L, Field P, Maier MA, Kraskov A, Kirkwood PA, Nakajima K, Lemon RN, Glickstein M (2014) Axon diameters and conduction velocities in the macaque pyramidal tract. J Neurophysiol 112:1229-1240. CrossRef Medline

Fritz N, Illert M, Kolb FP, Lemon RN, Muir RB, van der Burg J, Wiedemann E, Yamaguchi T (1985) The cortico-motoneuronal input to hand and forearm motoneurones in the anaesthetized monkey. J Physiol 366:20.

Geyer S, Ledberg A, Schleicher A, Kinomura S, Schormann T, BürgelU, Klingberg T, Larsson J, Zilles K, Roland PE (1996) Two different areas within the primary motor cortex of man. Nature 382:805-807. CrossRef Medline

Humphrey DR, Corrie WS (1978) Properties of pyramidal tract neuron system within a functionally defined subregion of primate motor cortex. J Neurophysiol 41:216-243. Medline

Isa T, Ohki Y, Seki K, Alstermark B (2006) Properties of propriospinal neurons in the $\mathrm{C} 3-\mathrm{C} 4$ segments mediating disynaptic pyramidal excitation to forelimb motoneurons in the macaque monkey. J Neurophysiol 95: 3674-3685. 10.1152/jn.00103.2005. CrossRef Medline

Jack JJ, Miller S, Porter R, Redman SJ (1971) The time course of minimal excitory post-synaptic potentials evoked in spinal motoneurones by group Ia afferent fibres. J Physiol 215:353-380. CrossRef Medline

Jankowska E, Padel Y, Tanaka R (1976) Disynaptic inhibition of spinal motoneurones from the motor cortex in the monkey. J Physiol 258:467-487. CrossRef Medline

Keizer K, Kuypers HG (1989) Distribution of corticospinal neurons with collaterals to the lower brain stem reticular formation in monkey (Macaca fascicularis). Exp Brain Res 74:311-318. Medline

Kinoshita M, Matsui R, Kato S, Hasegawa T, Kasahara H, Isa K, Watakabe A, Yamamori T, Nishimura Y, Alstermark B, Watanabe D, Kobayashi K, Isa $\mathrm{T}$ (2012) Genetic dissection of the circuit for hand dexterity in primates. Nature 487:235-238. CrossRef Medline

Koželj S, Baker SN (2014) Different phase delays of peripheral input to primate motor cortex and spinal cord promote cancellation at physiological tremor frequencies. J Neurophysiol 111:2001-2016. CrossRef Medline

Kujirai T, Caramia MD, Rothwell JC, Day BL, Thompson PD, Ferbert A, Wroe S, Asselman P, Marsden CD (1993) Corticocortical inhibition in human motor cortex. J Physiol 471:501-519. Medline

Maier MA, Illert M, Kirkwood PA, Nielsen J, Lemon RN (1998) Does a C3-C4 propriospinal system transmit corticospinal excitation in the primate? An investigation in the macaque monkey. J Physiol 511:191-212. Medline

Maier MA, Olivier E, Baker SN, Kirkwood PA, Morris T, Lemon RN (1997) Direct and indirect corticospinal control of arm and hand motoneurons in the squirrel monkey (Saimiri sciureus). J Neurophysiol 78:721-733. Medline

Murray EA, Coulter JD (1981) Organization of corticospinal neurons in the monkey. J Comp Neurol 195:339-365. CrossRef Medline

Nicolas G, Marchand-Pauvert V, Burke D, Pierrot-Deseilligny E (2001) Corticospinal excitation of presumed cervical propriospinal neurones and its reversal to inhibition in humans. J Physiol 533:903-919. CrossRef Medline

Olivier E, Baker SN, Nakajima K, Brochier T, Lemon RN (2001) Investigation into non-monosynaptic corticospinal excitation of macaque upper limb single motor units. J Neurophysiol 86:1573-1586. Medline

Porter R, Lemon RN (1993) Corticospinal function and voluntary movement. Oxford: Oxford UP.

Porter R, Muir RB (1971) The meaning for motoneurones of the temporal pattern of natural activity in pyramidal tract neurones of conscious monkey. Brain Res 34:127-142. CrossRef Medline

Rathelot JA, Strick PL (2006) Muscle representation in the macaque motor cortex: an anatomical perspective. Proc Natl Acad Sci U S A 103:82578262. CrossRef Medline

Rathelot JA, Strick PL (2009) Subdivisions of primary motor cortex based on cortico-motoneuronal cells. Proc Natl Acad Sci U S A 106:918-923. CrossRef Medline

Riddle CN, Baker SN (2010) Convergence of pyramidal and medial brain stem descending pathways onto macaque cervical spinal interneurons. J Neurophysiol 103:2821-2832. CrossRef Medline

Riddle CN, Edgley SA, Baker SN (2009) Direct and indirect connections with upper limb motoneurons from the primate reticulospinal tract. J Neurosci 29:4993-4999. CrossRef Medline

Sessle BJ, Wiesendanger M (1982) Structural and functional definition of the motor cortex in the monkey (Macaca fascicularis). J Physiol 323: 245-265. CrossRef Medline

Shimazu H, Maier MA, Cerri G, Kirkwood PA, Lemon RN (2004) Macaque ventral premotor cortex exerts powerful facilitation of motor cortex outputs to upper limb motoneurons. J Neurosci 24:1200-1211. CrossRef Medline

Soteropoulos DS, Baker SN (2009) Quantifying neural coding of event timing. J Neurophysiol 101:402-417. CrossRef Medline

Soteropoulos DS, Williams ER, Baker SN (2012) Cells in the monkey pontomedullary reticular formation modulate their activity with slow finger movements. J Physiol 590:4011-4027. CrossRef Medline

Stoney SD Jr, Thompson WD, Asanuma H (1968) Excitation of pyramidal tract cells by intracortical microstimulation: effective extent of stimulating current. J Neurophysiol 31:659-669. Medline

Strick PL, Preston JB (1982a) Two representations of the hand in area 4 of a primate. I. Motor output organization. J Neurophysiol 48:139-149. Medline

Strick PL, Preston JB (1982b) Two representations of the hand in area 4 of a primate. II. Somatosensory input organization. J Neurophysiol 48: 150-159. Medline

Takei T, Seki K (2010) Spinal interneurons facilitate coactivation of hand muscles during a precision grip task in monkeys. J Neurosci 30:17041-17050. CrossRef Medline

Tanji J, Wise SP (1981) Submodality distribution in sensorimotor cortex of the unanaesthetized monkey. J Neurophysiol 45:467-481. Medline

Ugolini G (2010) Advances in viral transneuronal tracing. J Neurosci Methods 194:2-20. CrossRef Medline

Wannier TM, Maier MA, Hepp-Reymond MC (1991) Contrasting properties of monkey somatosensory and motor cortex neurons activated during the control of force in precision grip. J Neurophysiol 65:572-589. Medline

Wetmore DZ, Baker SN (2004) Post-spike distance-to-threshold trajectories of neurones in monkey motor cortex. J Physiol 555:831-850. CrossRef Medline

Widener GL, Cheney PD (1997) Effects on muscle activity from microstimuli applied to somatosensory and motor cortex during voluntary movement in the monkey. J Neurophysiol 77:2446-2465. Medline

Williams ER, Soteropoulos DS, Baker SN (2009) Coherence between motor cortical activity and peripheral discontinuities during slow finger movements. J Neurophysiol 102:1296-1309. CrossRef Medline

Witham CL, Baker SN (2007) Network oscillations and intrinsic spiking rhythmicity do not covary in monkey sensorimotor areas. J Physiol 580: 801-814. CrossRef Medline

Yoshino-Saito K, Nishimura Y, Oishi T, Isa T (2010) Quantitative intersegmental and inter-laminar comparison of corticospinal projections from the forelimb area of the primary motor cortex of macaque monkeys. Neuroscience 171:1164-1179. CrossRef Medline

Zaaimi B, Edgley SA, Soteropoulos DS, Baker SN (2012) Changes in descending motor pathway connectivity after corticospinal tract lesion in macaque monkey. Brain 135:2277-2289. CrossRef Medline 